\title{
Rare syndromes of the head and face: mandibulofacial and acrofacial dysostoses
}

DOI:

10.1002/wdev.263

\section{Document Version}

Accepted author manuscript

Link to publication record in Manchester Research Explorer

\section{Citation for published version (APA):}

Terrazas, K., Dixon, J., Trainor, P. A., \& Dixon, M. (2017). Rare syndromes of the head and face: mandibulofacial and acrofacial dysostoses. Wiley Interdisciplinary Reviews: Developmental Biology, 6(3), [e263].

https://doi.org/10.1002/wdev.263

\section{Published in:}

Wiley Interdisciplinary Reviews: Developmental Biology

\section{Citing this paper}

Please note that where the full-text provided on Manchester Research Explorer is the Author Accepted Manuscript or Proof version this may differ from the final Published version. If citing, it is advised that you check and use the publisher's definitive version.

\section{General rights}

Copyright and moral rights for the publications made accessible in the Research Explorer are retained by the authors and/or other copyright owners and it is a condition of accessing publications that users recognise and abide by the legal requirements associated with these rights.

\section{Takedown policy}

If you believe that this document breaches copyright please refer to the University of Manchester's Takedown Procedures [http://man.ac.uk/04Y6Bo] or contact uml.scholarlycommunications@manchester.ac.uk providing relevant details, so we can investigate your claim.

\section{OPEN ACCESS}




\section{Rare syndromes of the head and face: mandibulofacial and acrofacial dysostoses}

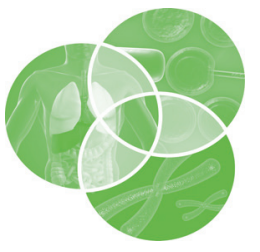

\section{Karla Terrazas, ${ }^{1}$ Jill Dixon, ${ }^{2}$ Paul A. Trainor ${ }^{1,3}$ and Michael J. Dixon ${ }^{2 *}$}

Craniofacial anomalies account for approximately one-third of all congenital birth defects reflecting the complexity of head and facial development. Craniofacial development is dependent upon a multipotent, migratory population of neural crest cells, which generate most of the bone and cartilage of the head and face. In this review, we discuss advances in our understanding of the pathogenesis of a specific array of craniofacial anomalies, termed facial dysostoses, which can be subdivided into mandibulofacial dysostosis, which present with craniofacial defects only, and acrofacial dysostosis, which encompasses both craniofacial and limb anomalies. In particular, we focus on Treacher Collins syndrome, Acrofacial Dysostosis-Cincinnati Type as well as Nager and Miller syndromes, and animal models that provide new insights into the molecular and cellut asis of these congenital syndromes. We emphasize the etiologic and pathoge similarities between these birth defects, specifically their unique deficiencies in global processes including ribosome biogenesis, DNA damage repair, and pre-mRNA splicing, all of which affect neural crest cell development and result in similar tissue-specific defects. ๑) 2016 Wiley Periodicals, Inc.

How to cite this article:

WIREs Dev Biol 2016, e263. doi: 10.1002/wdev.263

\section{INTRODUCTION}

$\mathrm{T}$ he craniofacial complex houses and protects the brain and most of the body's primary sense organs and is essential for feeding and respiration. Composed of nerves, muscles, cartilage, bone and connective tissue, head and facial development begins during early embryogenesis with formation of the frontonasal prominence and the pharyngeal arches, which are transient medial and lateral outgrowths of cranial tissue (Figure 1). The frontonasal prominence ultimately gives rise to the forehead and the nose,

\footnotetext{
*Correspondence to: mike.dixon@manchester.ac.uk

${ }^{1}$ Stowers Institute for Medical Research, Kansas City, MO, USA

${ }^{2}$ Division of Dentistry, Faculty of Biology, Medicine \& Healt Michael Smith Building, University of Manchester, Manchester, UK

${ }^{3}$ Department of Anatomy and Cell Biology, University of Kansas Medical Center, Kansas City, KS, USA
}

Conflict of interest: The authors have declared no conflicts of interest for this article. while the reiterated pattern of paired pharyngeal arches give rise to the jaws and parts of the neck. ${ }^{2}$ The basic structure of each prominence and arch is the same. Externally, they are composed of ectoderm, which with respect to the pharyngeal arches, forms the pharyngeal clefts or grooves. Internally, the frontonasal prominence and pharyngeal arches are lined with endoderm, which forms the pharyngeal pouches. At the junctions that separate the pharyngeal arches, the endoderm contacts the ectoderm by an active movement called out-pocketing. ${ }^{2-4}$ Between the ectoderm and endoderm epithelia is a mesenchymal core. In the frontonasal pron (nime the core is composed of neural crest cells (Nes), while in the pharyngeal arches the mesenchymal core is composed of both NCC and mesoderm. ${ }^{5,6}$ NCC are a multipotent progenitor cell population that is derived from the neuroepithelium, undergoes an epithelial to mesenchymal transformation, delaminates and then migrates, colonizing the frontonasal prominence and pharyngeal arches ${ }^{2,3}$ (Figure 1(a)-(c)). Collectively, these four tissues, ectoderm, endoderm, NCC, and 


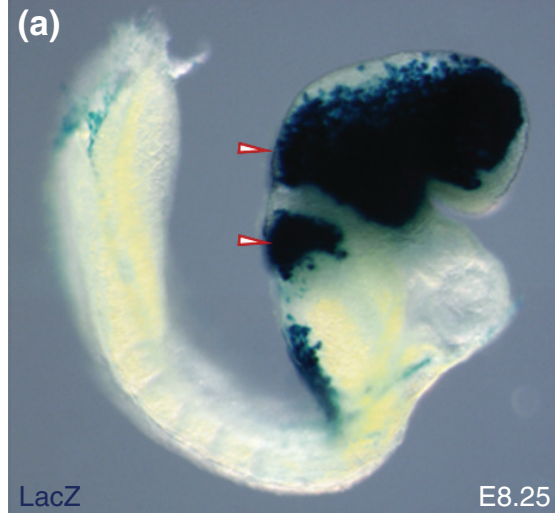

(d)

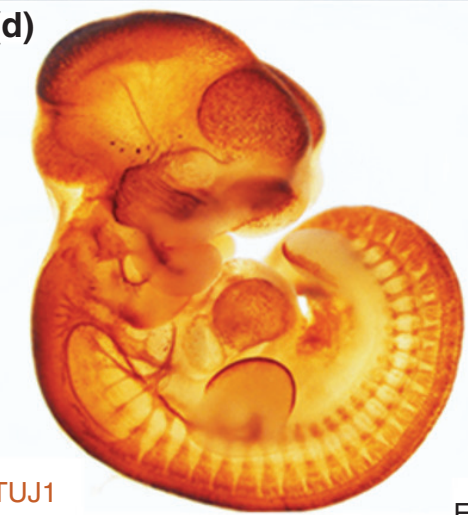

(e)

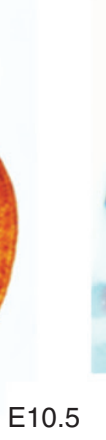

(e) (b)
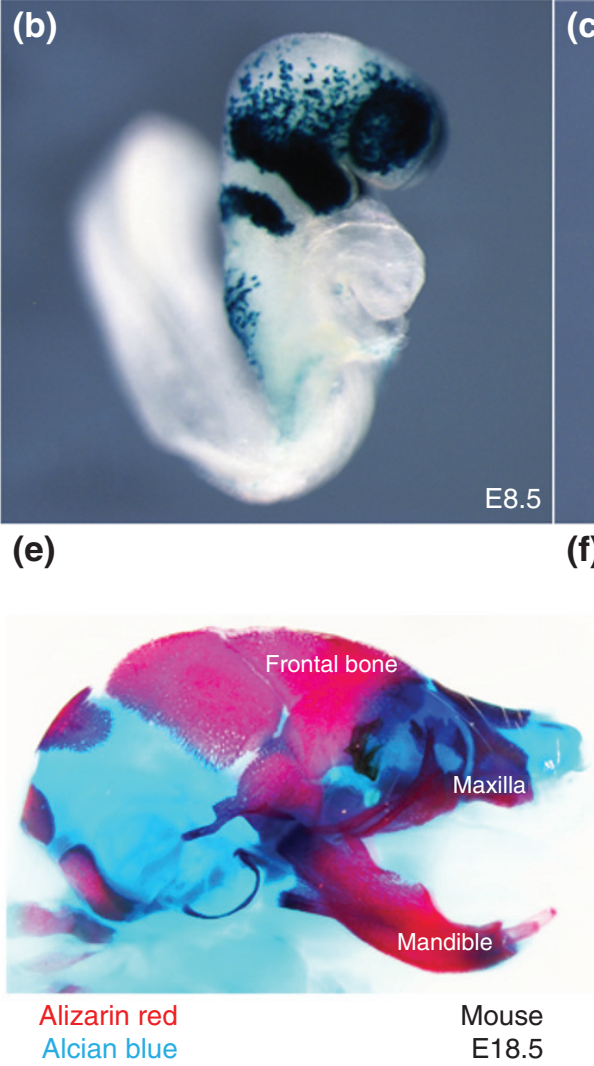

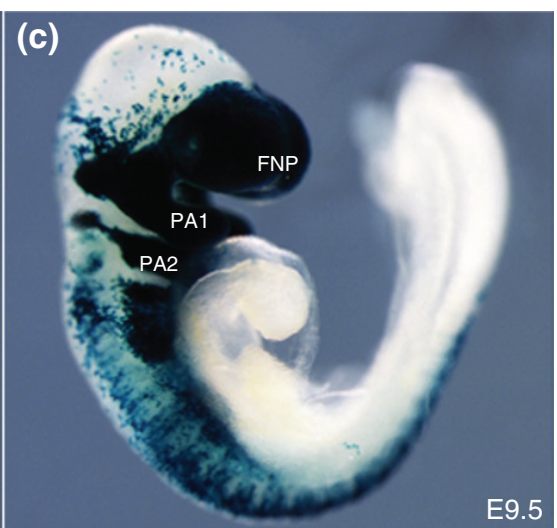

(f)

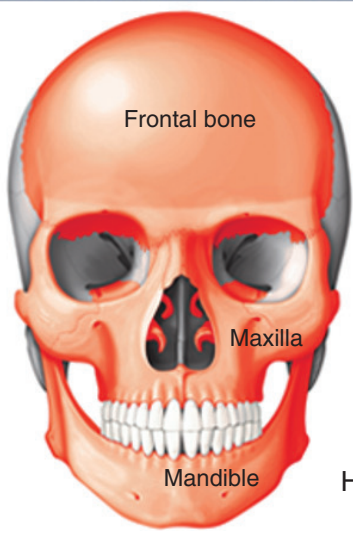

FIG URE 1 | Neural crest cells and craniofacial development. (a-c) Mef2c-F10N-Lacz whole-mount expression marking migrating neural crest cells as they migrate away from the dorsal neural tube to colonize the frontonasal prominence (FNP) and pharyngeal arches 1 and 2 (PA1,PA2). (d-f) NCC derivatives. (d) TUJ1 whole-mount immunostaining for NCC and placode-derived neurons. (e) Alizarin red and alcian blue staining for bone and cartilage, respectively. Frontal bone derived from the FNP, and maxilla and mandible derived from PA1. (f) Schematic of the NCCderived craniofacial bones of a healthy human adult. Frontal bone derived from the FNP, and maxilla and mandible derived from PA1.

mesoderm, interact to give rise to the skeletal, muscular, vascular, and nervous tissue elements of the head and neck $^{2,7,8}$ (Figure $\left.1(\mathrm{~d})-(\mathrm{f})\right)$. The complexity of craniofacial development renders it susceptible to developmental anomalies. Approximately one third of all congenital anomalies affect the head and face and, to date, more than 700 distinct craniofacial syndromes have been described.

The facial dysostoses describe a set of rare, clinically and etiologically heterogeneous anomalies of the craniofacial skeleton. Facial dysostoses arise as a consequence of abnormal development of the first and second pharyngeal arches and their derivatives, including the upper and lower jaw and their hyoid support structures. Facial dysostoses can be subdivided into mandibulofacial dysostosis and acrofacial dysostosis. Mandibulofacial dysostosis (OMIM610536) ${ }^{9}$ manifests at birth as maxillary, zygomatic, and mandibular hypoplasia (Figure 2), together with cleft palate, and/or ear defects. Many distinct mandibulofacial dysostosis syndromes have been described; however, clinically, the best understood is Treacher Collins syndrome (TCS; OMIM 154500)..$^{10-13}$ In contrast, acrofacial dysostoses present with craniofacial anomalies similar to those observed in mandibulofacial dysostosis but with the addition of limb defects. The acrofacial dysostoses include the well-characterized disorders of Miller syndrome (OMIM263750 $)^{14,15}$ and Nager syndrome $(\text { OMIM154400 })^{16-18}$ as well as more recently identified conditions such as Acrofacial DysostosisCincinnati type (OMIM616462). ${ }^{19}$

\section{TREACHER COLLINS SYNDROME}

TCS occurs with an incidence estimated at 1:50,000 live births. ${ }^{9,20}$ TCS is defined clinically by bilaterally symmetrical features that include hypoplasia (underdevelopment) of the facial bones, in particular the mandible (lower jaw) and zygomatic complex (cheek bones), coloboma (notching) of the lower eyelids; downward slanting of the palpebral fissures (opening 


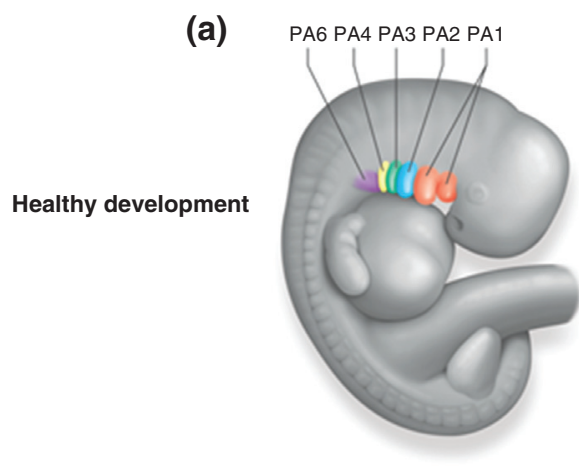

(c)

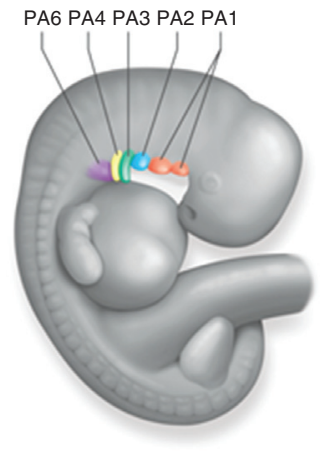

Mandibulofacia dysostosis
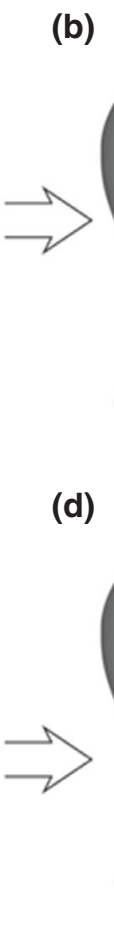

(d)

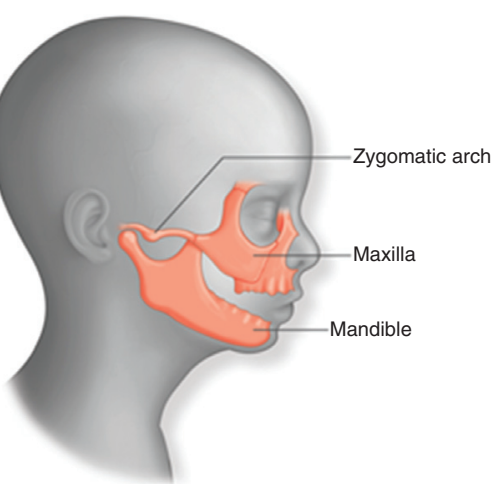

FIGURE 2 | Mandibulofacial dysostosis. (a) Schematic of the pharyngeal arches of a healthy human embryo. (b) Maxilla and mandible bone structures derived from neural crest cells that colonize the first pharyngeal arch. (c) Schematic of the pharyngeal arches of a human embryo with mandibulofacial dysostosis which arises as a consequence of hypoplastic first and second pharyngeal arches. (d) Hypoplastic maxilla and mandible bone structures observed in mandibulofacial dysostoses.

between the eyelids); microtia or atresia (underdevelopment or absence) of the external ears; narrowing of the ear canal, often resulting in conductive hearing loss (Figure 2); and micrognathia (small lower jaw) with or without cleft and/or high-arched palate. ${ }^{9,20,21}$ A considerable degree of interfamilial and, in multigeneration families, intrafamilial variation has been observed. ${ }^{11,12}$ In severely affected cases, TCS may result in perinatal death due to a compromised airway. ${ }^{13}$ In contrast, individuals may be so mildly affected that it can be difficult to establish an unequivocal diagnosis solely by clinical examination. Indeed, some patients are only diagnosed after the birth of a more severely affected child.

\section{The Genetic Basis of TCS}

A combination of genetic, physical, and transcript mapping led to the identifica of causative mutations for TCS in the gene 2 gnated TCOF1 on chromosome $5 \mathrm{q} 32$ in humans. ${ }^{10}$ The major TCOF1 transcript was found to comprise an open-reading frame of 4233 bp encoded by 26 exons. $^{22,23}$ However, two alternatively spliced exons, exon 6A and exon 16A, may also be present in the minor transcripts. ${ }^{24}$ Several hundred largely family-specific deletions, insertions, splicing, and nonsense mutations have subsequently been identified ${ }^{22,25-31}$ with partial gene deletions accounting for a small proportion of all mutations. ${ }^{32,33}$ The typical effect of the mutations is the introduction of a premature termination codon and the induction of nonsense-mediated mRNA degradation, leading to haploinsufficiency of TCOF1. This hypothesis is supported by the observation that cells derived from TCS patients exhibit significantly reduced levels of TCOF1, with the mutant allele being less abundant than its wild-type counterpart. ${ }^{34}$ To date, only a very small number of missense mutations have been identified and these all affect amino acid residues toward the N-terminus of the protein either within, or close to, a putative nuclear export signal. ${ }^{26,29}$ While usually characterized by an autosomal dominant mode of transmission, approximately $60 \%$ of cases do not have a previous family history and arise presumably as the result of a de novo mutation. ${ }^{35}$ It is important to note, however, there is at least one reported case of recessive inheritance in association with TCS. $^{36}$ In this instance, a homozygous nonsense mutation in TCOF1 was identified in an individual in which the 
carrier parents were completely normal clinically. The mutation was likely previously missed by direct Sanger sequencing, due to the expectation of a heterozygous sequence chromatogram peak given the characteristic autosomal dominant nature of the disease.

Collectively, about $80 \%$ of TCS cases are thought to be caused by mutations in TCOF1, which encodes the nucleolar phosphoprotein, Treacle (Figure 3). As all the large, multigeneration TCS families analyzed exhibited linkage to polymorphic markers within human chromosome 5q32, TCS was originally considered to be genetically homogeneous. However, despite extensive searches, the causative mutation in a subset of patients exhibiting classic features of TCS remained unidentified. The use of genome-wide copy number analysis in a child with TCS who was negative for a TCOF1 mutation, led to the identification of a de novo 156-kb deletion within human chromosome $13 \mathrm{q} 12.2$ that resulted in deletion of the entire POLR1D gene. ${ }^{37}$ POLR1D encodes a subunit of RNA polymerase I and III (Figure 3). ${ }^{37}$ Subsequently, a further 242 individuals with classic features of TCS, but who were negative

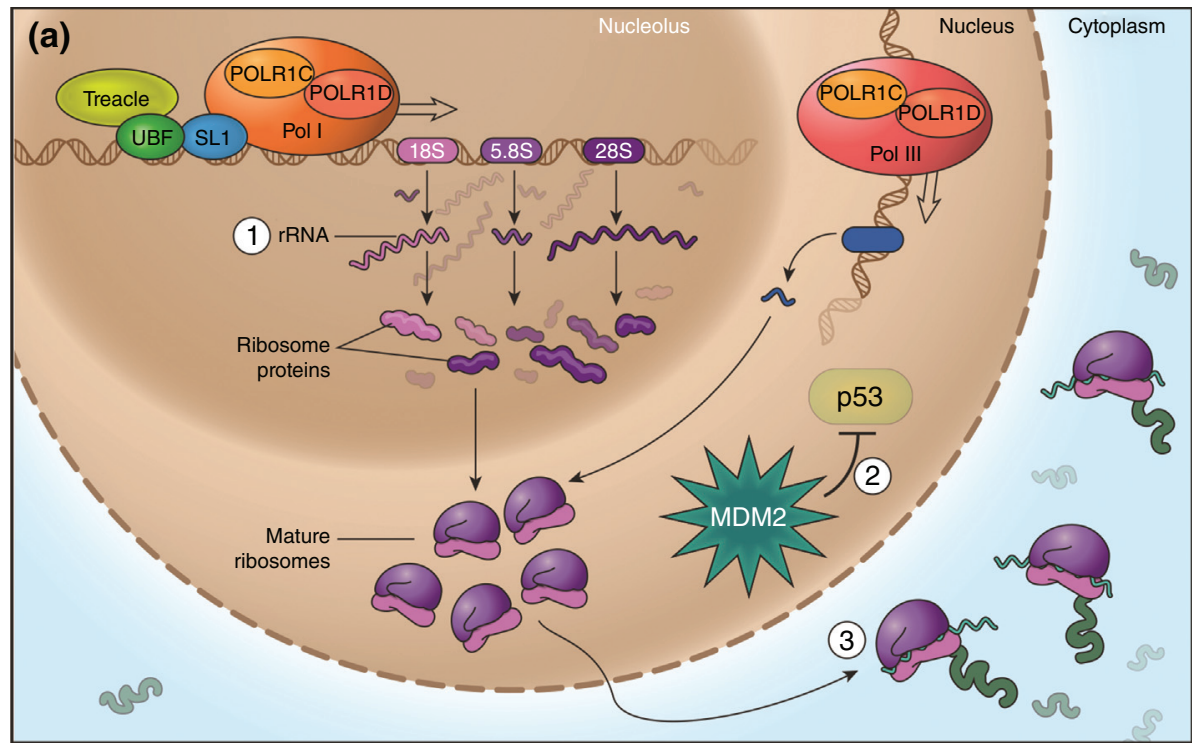
2 , ribosomal proteins bound to MDM2 causing a conformational change leading to enhanced p53 expression; and 3, decreased protein synthesis, 
for TCOF1 mutations, were sequenced, leading to the identification of additional POLR1D mutations. ${ }^{37}$ In addition to 10 heterozygous nonsense mutations, seven heterozygous missense mutations located in exon 3 of POLR1D were discovered. ${ }^{37}$ Without exception, the missense mutations affected evolutionary-conserved amino acids in the RNA polymerase dimerization domain of POLR1D. ${ }^{37}$ Given the strong interaction between POLR1D (RPAC2) and POLR1C (RPAC1) in yeast, ${ }^{38}$ POLR1C, which also encodes a subunit of RNA polymerase I and III (Figure 3), was sequenced leading to the identification of mutations in both POLR1C alleles in three affected individuals. In all cases, one mutant allele was inherited from each phenotypically unaffected parent, confirming autosomal recessive inheritance in a very small subset of TCS patients (OMIM248390)..$^{37,39}$

\section{The Biochemical Basis of TCS: The Role of Treacle in Ribosome Biogenesis}

TCOF1 encodes the low complexity, nucleolar phosphoprotein Treacle which contains putative nuclear export and nuclear import signals at the $\mathrm{N}$ - and and C-termini, respectively, together with a central repeat domain which is subject to a high degree of phosphorylation by casein kinase 2.22,23,40 Immunofluorescence studies indicated that Treacle exhibits nucleolar localization dependent upon C-terminal motifs, ${ }^{41,42}$ and subsequently, Treacle was shown to colocalize with UBF, one of two transcription factors required for accurate transcription of human ribosomal RNA genes by RNA polymerase I (PolI) (Figure 3). These observations suggested an association between Treacle and the ribosomal DNA transcription machinery. ${ }^{43}$ Immunoprecipitation and yeast two-hybrid analyses confirmed a direct interaction between Treacle and UBF, and siRNA-mediated knockdown of Treacle in vitro resulted in inhibition of rDNA transcription. ${ }^{43}$ Downregulation of Treacle expression also resulted in decreased methylation of $18 \mathrm{~S}$ pre-rRNA ${ }^{44}$ possibly via its interaction with NOP56 protein, ${ }^{45}$ a component of the pre-rRNA methylation complex.

Recent studies have demonstrated that Treacle functions as a stable constituent in the PolI complex independent of UBF by associating with PolI through its central repeat domain, whereas the C-terminus of Treacle interacts with UBF, human Nopp140, and the rDNA promoter. ${ }^{46}$ Importantly, depletion of Treacle drastically alters the localization of UBF and PolI indicating an essential role for Treacle in nucleolar retention of these two proteins, possibly by acting as a scaffold protein to maintain Poll in the nucleolus. ${ }^{46}$ Deletion constructs engineered to mimic mutations observed in TCS patients demonstrated that, in the presence of endogenous Treacle, C-terminal deletions did not alter PolI localization nor block prerRNA transcription. ${ }^{46}$ These data indicate that the C-terminal truncations of Treacle do not act in a dominant-negative manner and provide further evidence that the craniofacial features of TCS patients are the result of TCOF1 haploinsufficiency.

\section{The Cellular Basis of TCS: The Role of Treacle in Neuroepithelial Survival and NCC Proliferation}

The first insights into the developmental pathogenesis of TCS were derived from expression analyses in mouse embryos, which indicated that although the murine orthologue of TCOF1 was widely expressed, the highest levels were observed in the neuroepithelium and in NCC-derived facial mesenchyme. ${ }^{47,48}$ Subsequently, a mouse model of TCS was generated using gene targeting to replace exon 1 of Tcof 1 with a neomycin-resistance cassette. ${ }^{49}$ Tcof $1^{+/-}$neonatal mice exhibit severe craniofacial anomalies exceeding the spectrum of those observed in TCS patients, including exencephaly, abnormal development of the maxilla, hypoplasia of the mandible, anophthalmia, and agenesis of the nasal passages, resulting in death shortly after birth due to asphyxia. ${ }^{49}$ The facial phenotype was subsequently found to be strongly dependent on the genetic background on which the mutation was placed, ranging from neonatal lethality in three strains of mice, including $\mathrm{C} 57 \mathrm{BL} / 6$, to viable and fertile in two others, DBA and BALB/c, allowing the mutation to be maintained and evaluated in these backgrounds. ${ }^{50}$

Although $T c o f 1^{+/-} / \mathrm{DBA}$ mice appear grossly normal, they exhibit abnormalities in middle ear cavitation and growth of the auditory bullae resulting in profound conductive hearing loss. ${ }^{51}$ Notably, Tcof $1^{+/} / \mathrm{DBA}$ mice also exhibit significant hypoplasia of the brain compared with their wild-type littermates even though there is no difference in the body weight between the different genotypes. ${ }^{52}$ The microcephaly observed in the mutant mice arises from an anomaly in neural progenitor maintenance. ${ }^{52}$ In this context, Treacle localizes to the centrosomes and kinetochores in mitotic cells, and its interaction with Polo-like kinase 1 ( $\mathrm{Plk} 1$ ) is essential for the control of spindle orientation, mitotic progression, and subsequent maintenance of neural progenitor cells during brain development. ${ }^{52}$ 
Crucially, intercrossing Tcof $1^{+/-}$DBA mice onto the C57BL/6 background yielded heterozygous embryos that displayed a consistent phenotype with features highly similar to those observed in TCS patients. These features include deficiencies of the nasal and frontal bones, the premaxilla, maxillary, and palatine bones, as well as cleft palate. ${ }^{48}$ More detailed investigation of the palatal anomalies observed in the $\mathrm{Tcof} 1^{+/-}$mice indicated that while $46 \%$ exhibited either a complete cleft of the secondary palate $(6 \%)$ or a cleft affecting the soft palate only $(40 \%)$, the remainder displayed high-arched palate with reductions in palatal length and width. ${ }^{53}$

Analysis of embryos on a mixed DBA:C57BL/6 background revealed no differences in the patterns of NCC migration between $T c o f 1^{+-}$and wild-type embryos, ${ }^{48}$ thus disproving the long-held hypothesis of perturbed NCC migration as a cause of TCS. ${ }^{54}$ What was apparent, both from lineage tracing and molecular markers of NCC, such as Sox10, was that fewer crest cells appeared to migrate from the neural folds into the developing facial complex. ${ }^{48}$ Flow cytometry analyses of GFP-labeled NCC indicated that there were $22 \%$ fewer migrating NCC in Tcof $1^{+/-}$embryos compared to their wild-type littermates, resulting in hypoplastic cranial sensory ganglia and skeletal elements. TUNEL staining in combination with DiI tracing in vivo to delineate the earliest waves of migrating crest cells at E8.0 to E8.5, demonstrated conclusively that migrating NCC were viable in $\mathrm{Tcof1}^{+/-}$embryos. However, elevated levels of cell death were observed throughout the neuroepithelium, suggesting that Treacle was essential for the viability of neuroepithelial cells and progenitor NCC. $^{48}$ Furthermore, BrdU labeling of E8.5-E9.0 embryos revealed a significant reduction of proliferation in neuroepithelial cells and in neural crestderived cranial mesenchyme, effects that correlated with the spatiotemporal expression pattern of Tcof1. ${ }^{48}$

Importantly, Tcof1 haploinsufficient mouse embryos displayed a significant reduction in prerRNA levels, confirming Treacle plays a crucial role in ribosomal RNA production and subsequent ribosome biogenesis, ${ }^{43}$ which is essential for cell growth and proliferation. ${ }^{55}$ Treacle's role in ribosome biogenesis has also been documented using the Y10B antibody, which recognizes epitopes of $\mathrm{rRNA}^{56}$ and is used as a marker of mature ribosomes. ${ }^{56}$ Homotypic transplantation of Di-labeled midbrain and hindbrain tissue demonstrated that Treacle functions cellautonomously to promote neuroepithelial and progenitor NCC proliferation and survival through dynamic regulation of the spatiotemporal production of mature ribosomes in neuroepithelial cells and NCC. ${ }^{48}$

Consistent with these observations, a recent study also proposed a link between Treacle and ribosome biogenesis associated factors in NCC development. ${ }^{57}$ More specifically, the cullin-RING ligase proteins comprise the largest class of ubiquitination enzymes, and the vertebrate-specific CUL3 adapter protein KBTBD8 was shown to be an essential regulator of NCC specification through ubiquitination of Treacle and the nucleolar and coiled-body phosphoprotein 1 (NOLC1). ${ }^{57}$ Formation of a TreacleNOLC1 complex connects RNA PolI with enzymes responsible for ribosomal processing and modification. ${ }^{57}$ Ultimately, the KBTBD8-dependent assembly of a ribosome modification platform remodels the translational program of differentiating cells undergoing neural conversion in favor of NCC specification. ${ }^{57}$ However, these studies, which were performed in Xenopus embryos, were based solely on gene expression which is not an indicator of lineage and need to be evaluated by rigorous lineage tracing for the presence of NCC as well as be repeated in other model systems.

\section{Prevention of TCS through Inhibition} of p53 Function

A key breakthrough in our understanding of the role of Treacle came from microarray analyses of $T c o f 1^{+/-}$ embryos and their wild-type littermates which revealed that many well-recognized targets and mediators of p53-dependent transcription were upregulated in $T c o f 1^{+-}$embryos. ${ }^{58}$ These included Cong1, Trp53inp1, Pmaip1, Perp, and Wig1 which have been linked to diverse cellular processes such as cellcycle regulation, apoptosis, senescence, and DNA repair. ${ }^{58,59}$ This observation suggested a strong correlation between Tcof1 haploinsufficiency and p53dependent cell-cycle arrest and apoptosis. p53 protein is rapidly degraded under normal physiological conditions (Figure 3); however, immunohistochemistry using an anti-p53 antibody revealed elevated levels of p53 in the neuroepithelium of $\mathrm{Tcof1} 1^{+/-}$ embryos, providing a conclusive link between p53 stabilization, neuroepithelial cell death, and the subsequent deficiency of migrating crest cells. Moreover, this to the hypothesis that inhibition of p53 function mingt ameliorate, or even prevent, the key features of TCS in Tcof $1^{+/-}$embryos. ${ }^{58}$

Subsequently, daily administration of pifithrin$\alpha$, a chemical inhibitor of p53-dependent transcription and apoptosis, ${ }^{60}$ from E6.5 to E8.5, was shown to substantially reduce neuroepithelial apoptosis in 
Tcof $1^{+/-}$embryos. Remarkably, administration of pifithrin- $\alpha$ from E6.5 to E17.5 resulted in a partial rescue of the cranioskeletal abnormalities. ${ }^{58,60}$ These results paved the way for genetic crosses between p53 mutant mice and $\mathrm{Tcof} 1^{+/-}$mice, and subsequent assays for apoptosis using anti-caspase 3 immunostaining revealed p53 inhibition suppressed neuroepithelial cell death in E8.5 $\mathrm{Tcof}^{+/-}$embryos in a dosedependent manner. ${ }^{58}$ Removal of a single copy of p53 was sufficient to restore post-natal viability in all Tcof $^{+/-}$mice. Q Orever, the craniofacial abnormalities were resculum only about half of the Tcof $1^{+/-}$ Trp $53^{+/-}$newborn mice. ${ }^{58}$ The remaining $50 \%$ of Tcof $1^{+/-} / \operatorname{Tr} p 53^{+/-}$newborn mice still exhibited some degree of frontonasal hypoplasia. ${ }^{58}$ In contrast, all $\mathrm{Tcof1}^{+/-}$heterozygotes with complete loss of p53 function $\left(T c o f 1^{+-/} / \operatorname{Tr} p 53^{-/-}\right)$exhibited a near complete suppression of neuroepithelial apoptosis, and consequently a restoration of the NCC population which resulted in normal craniofacial morphology indistinguishable from their wild-type littermates. ${ }^{58}$ Surprisingly, prevention of the abnormalities characteristic of TCS occurred without altering or restoring ribosome production, distinguishing p53-dependent neuroepithelial apoptosis from deficient mature ribosome biogenesis as the primary cause of TCS craniofacial anomalies. ${ }^{58}$ Nevertheless, p53 inhibition is not a viable therapeutic treatment for the amelioration of TCS due to it increasing the risk of malignancy.

\section{The Role of Treacle in the DNA Damage Response}

Recent research has shown that Treacle also plays a fundamental role in the DNA damage response pathway which is activated to maintain genome integrity. Treacle colocalizes with P-ATM (phosphorylated -ataxia telangiectasia mutated protein) and $\operatorname{Rad} 50$ (a protein involved in DNA double-strand break repair) to DNA lesions in association with DNA damage. ${ }^{61}$ More specifically, Treacle interacts physically with the MRN complex (a protein complex consisting of Mre11, $\operatorname{Rad} 50$, and Nbs1), ${ }^{61}$ which recruits ATM to DNA double-strand breaks where it phosphorylates $\mathrm{H} 2 \mathrm{AX}$ (H2A histone family, member $\mathrm{X})$, in response to DNA damage. This newly phosphorylated histone is then responsible for recruiting DNA repair proteins to the damage sites. ${ }^{62}$ Based on these observations, it was hypothesized that the neuroepithelial cell death observed in $T c o f 1^{+/}$embryos might be associated with DNA damage in vivo. Consistent with this idea, immunostaining indicated that $\gamma \mathrm{H} 2 \mathrm{AX}$, which occurs via phosphorylation of $\mathrm{H} 2 \mathrm{AX}$ by ATM at double-strand breaks in response to DNA damage ${ }^{62}$ was present in neuroepithelial cells of E8.5 $\mathrm{Tcof}^{+/-}$embryos. $^{61}$ Furthermore, $\gamma \mathrm{H} 2 \mathrm{AX}$ positive neuroepithelial cells were labeled with phosphorylated Chk2 (cell cycle checkpoint kinase 2), a protein that transmits the DNA damage response signal to the apoptotic pathway and caspase 3 (a marker of apoptosis). ${ }^{61}$ Interestingly, treating wild-type embryos with 3-nitropropionic acid, a potent inducer of reactive oxygen species (ROS), results in a substantial increase in neuroepithelial cell death. ${ }^{61}$ Thus, compared with cells of the nonneural ectoderm, mesoderm and endoderm, the neuroepithelium exists in a highly oxidative state and is very sensitive to exogenous oxidative stress. ${ }^{61}$ Consequently, it was proposed that Tcof1 loss of function or haploinsufficiency could increase a cell or tissue's sensitivity to oxidative stress-induced DNA damage. Consistent with this idea, dietary supplementation of Tcof $1^{+-}$embryos with $\mathrm{N}$-acetylcysteine, a strong antioxidant, reduced the number and size of DNA damage-induced foci, diminished the level of neuroepithelial apoptosis, and substantially ameliorated the craniofacial anomalies observed in Tcof $1^{+/-}$ mice. ${ }^{61}$ Together these results suggest that antioxidant supplementation may provide a therapeutic avenue for the prevention of TCS.

In parallel studies, DNA damage was shown to induce the recruitment of Nijmegen breakage syndrome protein 1 (NBS1) into the dense fibrillar component of the nucleoli where it silences ribosomal RNA transcription. ${ }^{63,64}$ Furthermore, NBS1 was shown to bind Treacle directly and that an Nbs1Treacle complex controls rRNA transcription in response to DNA damage. ${ }^{63,64}$ Thus, Treacle, in addition to its role in ribosome biogenesis, facilitates the preservation of genomic stability after DNA damage ${ }^{63,64}$ and importantly links these two critical processes together. ${ }^{61}$

\section{The Biochemical and Molecular Basis of TCS; The Role of POLR1C and POLR1D in Ribosome Biogenesis}

Although the effects of TCOF1 mutations in the pathogenesis of TCS have been studied extensively, less is known about the molecular basis behind POLR1C or POLR1D mutations in the context of TCS. However, the first insights into the roles of both polr1c and polr1d in vertebrate development were recently described in zebrafish. ${ }^{65,66}$ Similar to Tcof1 in the mouse embryo, polr1c is ubiquitously expressed throughout the zebrafish embryo with elevated levels in specific tissues including the eye, 
1 midbrain, central nervous system, and the pharyngeal 2 arches and their derivatives, such as Meckel's cartilage and the lower jaw. ${ }^{65,66} \mathrm{~A}$ comparable expression pattern is also observed for polr $1 d .^{65}$ Consistent with these observations, alcian blue staining revealed that in both polr1 $c^{-1-}\left(\text { polr1 } 1 c^{(\mathrm{hi1124Tg})}\right)^{65,66}$ and polr1 $d^{-/-}$ (polr1 $\left.d^{(\text {hi2393Tg) }}\right)^{65}$ zebrafish, cartilage elements such as the palatoquadrate and Meckel's cartilage were hypoplastic, mimicking defects observed in TCS patients. Since the majority of the craniofacial cartilage is NCC-derived, a variety of markers for different phases of NCC development were tested via in situ hybridization to understand the roles of porl1c and polr1d in NCC development. Analysis of sox2, a marker for NCC specification and formation, and sox10 and foxd3, as markers of premigratory and migratory NCC, revealed that NCC specification, formation and migration occurred appropriately in polr $1 c^{-/-}$and polr $1 d^{-/-}$mutant embryos. ${ }^{65,66} \mathrm{How}^{-}$ ever, diminished domains of $d l x 2$ expression indicated a reduction in the number of mature NCC populating the pharyngeal arches. In agreement with this observation, Fli1a:egfp which labels postmigratory NCC, also revealed a significant reduction in the size of the pharyngeal arches in mutant embryos compared to that of controls. ${ }^{65}$

Collectively, these results raised the question of whether increased cell death or decreased cell proliferation was the underlying cause of the diminished number of NCC colonizing the pharyngeal arches in polr1c or polr1d mutant zebrafish. TUNEL staining revealed a significant increase in cell death in the neuroepithelium, affecting premigratory NCC progenitors, but no cell death was observed in migratory NCC in polr1c or polr1d mutants. ${ }^{65}$ Interestingly, however, apoptosis was detected in the lower jaw and pharyngeal region of $5 \mathrm{dpf}$ polr1c mutant zebrafish, suggesting a late embryonic role for polr $1 c$ in cell survival during skeletal differentiation in addition to its earlier role in the neuroepithelium. ${ }^{66}$ Moreover, the cell death observed in polr1c and polr1d zebrafish was p53 endent and genetic inhibition of p53 was able to suppress neuroepithelial apoptosis and ameliorate the craniofacial anomalies in polr $1 c$ and polr1d mutants. ${ }^{65}$

QRT-PCR, together with polysome profiling, revealed significantly reduced ribosome biogenesis in both polr1c and polr1d mutant embryos. ${ }^{65}$ Therefore, similar mechanisms underlie the pathogenesis of TCS irrespective of whether TCOF1, POLR1C, or PORL1D is mutated. These discoveries have provided insights into the tissue-specific role of ribosome biogenesis during embryonic development and disease and, more importantly, have opened exciting avenues for the possible prevention of TCS and other craniofacial congenital anomalies.

\section{ACROFACIAL DYSOSTOSIS- CINCINNATI TYPE}

Acrofacial dysostosis describes a congenital syndrome which presents with craniofacial defects similar to those observed in mandibulofacial dysostosis (Figure 2) but with the addition of limb defects. ${ }^{19,67}$ Acrofacial Dysostosis-Cincinnati type was recently defined in three affected individuals with variable phenotypes ranging from mild mandibulofacial dysostosis to more severe acrofacial dysostosis. ${ }^{19}$ All three patients presented with variable craniofacial phenotypes similar to those observed in TCS, including hypoplasia of the zygomatic arches, maxilla and mandible; severe micrognathia; downslating palpebral fissures; coloboma or inferiorly displaced orbits; bilateral anotia; and conductive hearing loss. Additionally, similar to other acrofacial dysostoses, two out of three patients presented with limb anomalies, including short bowed femurs; delayed epiphyseal ossification; flared metaphysis and dysplastic acetabula, while the other patient presented with short and broad fingers and toes. ${ }^{19}$ Interestingly, all three individuals were found to carry a heterozygous mutation in POLR1A, which encodes the largest subunit of RNA polymerase I, which is responsible for transcribing rRNA. ${ }^{19}$

Polr1a is initially expressed ubiquitously in zebrafish embryos before becoming enriched in cranial tissues including the brain, eyes and otic vesicles, as well as the somites and presumptive fins. ${ }^{19}$ Similar to the domains of activity and functional roles of Tcof1, polr1c and polr1d, it was hypothesized that mutations in POLR1A would also perturb rRNA transcription and ribosome biogenesis thereby disrupting NCC and craniofacial development during embryogenesis. Consistent with this idea, homozygous polr1 $a^{-/-}$(polr1a hi3639Tg $)$zebrafish embryos exhibit craniofacial defects mimicking the phenotypes observed in individuals with Acrofacial DysostosisCincinnati type. ${ }^{19}$ Reduced expression of the NCC markers: sox10, sox 9 and $d l \times 2$, indicated that deficiencies in NCC are the cause of the craniofacial malformations in polr1a mutant zebrafish. TUNEL assays subsequently revealed that polr $1 a$ is required for neuroepithelial cell survival and the generation of NCC but is not required for the survival of migrating NCC ${ }^{19}$ which is similar to the established roles of Tcof1, polr1c and polr1d.

Analyses of $\mathrm{Tcof}^{+/-}$mice, and polr $1 c^{-/-}$and polr $1 d^{-1-}$ zebrafish, demonstrated that neuroepithelial 
and NCC progenitor cell death was caused by deficient ribosome biogenesis, which resulted in nucleolar stress activation of $\mathrm{p} 53 .^{48,65}$ QRT-PCR and immunoblot assays revealed a similarly significant reduction of rRNA transcription in association with increased p53 in polr1a $a^{\text {hi3639Tg }}$ mutant embryos. ${ }^{19}$ Collectively, these results illustrate important tissuespecific roles for ribosome biogenesis, specifically in development of the neuroepithelium and NCC, as well as possibly their derivatives such as craniofacial cartilage and bone. To better understand the tissue-specific roles of ribosome biogenesis during embryogenesis, it will be necessary to generate conditional, tissue-specific, loss-of-function models for Tcof1, Polr1a, Polr1c and Polr1d, as well as animal models targeting other ribosomal genes.

\section{Mandibulofacial Dysostosis with Microcephaly}

Mandibulofacial dysostosis with microcephaly (MFDM), which is also known as mandibulofacial dysostosis (Figure 2), Guion-Almeida type (MFDM; MFDGA;MIM 610536) represents a subgroup of individuals with acrofacial dysostosis that also present with microcephaly. ${ }^{68}$ MFDM is characterized primarily by midface hypoplasia, downward slanting of the palpebral fissures, unusually small jaw (Figure 2), abnormalities of the external ears, which can lead to conductive hearing loss, and occasional abnormalities of the thumbs. ${ }^{67,68}$ This syndrome was described as the first multiple-malformation syndrome primarily attributed to a defect in the major spliceosome, which is responsible for removing introns from transcribed pre-mRNA. ${ }^{67,68}$ Recently, whole-exome sequencing studies revealed causative mutations in EFTUD2, which encodes a subunit of two complexes termed the major and the minor spliceosomes. ${ }^{69} \mathrm{Sim}-$ ilar to TCS, a wide variety of mutation types have been identified in patients with MFDM, including nonsense and missense mutations, large deletions, frame-shifts and splice-site mutations, all of which are consistent with haploinsufficiency. ${ }^{67,70}$ Interestingly, eftud2 is ubiquitously expressed with enriched levels in the head, brain, tectum, eye and pharyngeal arches of zebrafish embryos. ${ }^{71}$ Unfortunately, zebrafish embryos homozygous for eftud2 mutations die prior to $2 \mathrm{dpf}$ while heterozygotes do not show any noticeable phenotypes compared to their wild-type siblings. ${ }^{71}$ The phenotypes present in MFDM patients have been proposed to arise due to the aberrant splicing of genes specifically involved in NCC and/or bone development. ${ }^{69}$
Recently, a novel mutation in EFTUD2 was identified in a patient with microphthalmia, anophthalmia and coloboma (MAC). ${ }^{71}$ To date, no known EFTUD2-positive MFDM patients develop any abnormalities of the eye and it is possible that this is because individuals with MAC carry a secondary mutation that has yet to be identified. ${ }^{71}$ However, this discrepancy could also simply reflect the small number of reported cases with MFDM. Alternatively, the eye anomalies characteristic of MAC could be caused by an interaction between mutations in EFTUD2 and other genes involved in eye development. ${ }^{71}$ To understand these mechanisms, screening for eye anomalies in MFDM patients and for craniofacial anomalies in MAC patients is needed. It will also be critical to understand the mechanisms and developmental roles of EFTUD2 in mammalian development. Therefore, in the future, it will be necessary to generate conditional loss-of-function animal models and also recapitulate the human mutations to better understand the role of EFTUD2 and splicing during development and in the pathogenesis of MFDM and MAC.

\section{Nager Syndrome}

Nager syndrome (OMIM \#154400) is the most frequent and well-studied type of acrofacial dysostosis. In addition to the overlapping craniofacial phenotypes with MFDM and TCS, including downward slanting of the palpebral fissures (Figure 2), Nager syndrome was identified as an acrofacial dysostosis condition due to the presence of preaxial limb defects, most commonly hypoplasia or absence of the thumbs. ${ }^{72,73}$ The similar phenotypes observed in Nager syndrome in comparison to other facial dysostoses, plus the small number of reported cases $(n=100)$, makes diagnosis and identification of common mutations in Nager syndrome challenging. ${ }^{67}$ Despite these limitations, recent studies identified mutations in SF3B4 in about $60 \%$ of Nager syndrome cases. ${ }^{74}$ Similar to TCS, Nager syndrome is rare and is primarily associated with de novo mutations, although both autosomal dominant and autosomal recessive mutations have also been reported. ${ }^{16-18,75}$

SF3B4 (Splicing factor 3b, subunit 4), encodes spliceosome-associated protein 49 , which is a component of the pre-mRNA spliceosome complex that removes introns from pre-mRNAs during the production of mature mRNAs. ${ }^{74,76} \mathrm{Sf} 3 \mathrm{~b} 4$ expression in Xenopus embryos was reported to be ubiquitous with elevated levels in the pharyngeal arches and developing eyes. ${ }^{72}$ Similar to ribosome biogenesis in 
1 the conte $\Omega$ TCS, the spliceosome complex may 2 act tissue cifically in the context of Nager syndrome. Consistent with this idea, translation blocking morpholino knockdown of Sf3b4 in Xenopus embryos resulted in a decrease in NCC progenitors as a consequence of cell death. ${ }^{72}$ The specificity of the defects suggests that aberrant splicing of genes involved in NCC, craniofacial and limb development may be an underlying cause of the Nager syndrome phenotypes of the craniofacial and preaxial skeleton.

It has also been proposed that SF3B4 mutations might cause Nager syndrome via mechanisms unrelated to a role in splicing. ${ }^{67,72}$ In support of this idea, a yeast two-hybrid screen using SFSB4 as bait identified downstream targets of BMP signaling which play important roles in craniofacial and limb development. ${ }^{77}$ SF3B4 inhibits BMP-2 (bone morphogenetic protein-2)-mediated osteogenic and chondrogenic differentiation, which suggests that in addition to its roles in mRNA splicing, SF3B4 may also inhibit BMP-mediated osteochondral cell differentiation. ${ }^{78}$ Therefore, it will be important to study noncanonical roles of SF3B4, as it is possible that similar to the roles of Tcof1 in DNA damage repair in the context of TCS, SF3B4 acts tissue specifically through yet undetermined mechanisms.

\section{Miller Syndrome}

Miller syndrome (OMIM263750), also termed postacrofacial dysostosis (POADS), Genee-Wiedemann, and Wildervanck-Smith syndromes, is classified as an acrofacial dysostosis disorder. ${ }^{79}$ Similar to TCS and Nager syndromes, Miller syndrome is characterized by the craniofacial abnormalities such as downward slanting of the palpebral fissures, coloboma of the lower eyelid, hypoplasia of the zygomatic complex (Figure 2), micrognathia, and microtia, which can lead to conductive hearing loss. ${ }^{79}$ Signifying Miller syndrome as a form of acrofacial dysostosis is the presence of postaxial limb defects, which contrasts with the preaxial defects presented by Nager syndrome. $^{79}$

Miller syndrome was the first Mendelian syndrome whose molecular basis was identified via whole-exome sequencing, and was found to correlate with autosomal recessive or compound heterozygous mutations in dibydroorotate debydrogenase (DHODH). ${ }^{80}$ DHODH encodes a key enzyme in the de novo pyrimidine synthesis pathway and mitochondrial electron transport chain. Until recently, it remained unclear how DHODH gene mutations led to the defects characteristic of Miller syndrome. Furthermore, similar to the facial dysostoses described above, the mechanisms by which global processes, such as pyrimidine synthesis and the mitochondrial electron transport chain cause tissue-specific defects remained a mystery. However, treating zebrafish with leflunomide, a DHODH inhibitor, led to almost complete abrogation of NCC and a reduction of NCC self-renewal in association with inhibition of transcriptional elongation of neural crest genes. ${ }^{81}$ Analogous to TCS, this gests that mutations in $\mathrm{DHDOH}$ lead to apoptosis of NCC progenitors, which results in a decrease in the number of migrating NCC and consequently defects in the craniofacial skeleton. Additionally, similar to the role of $T \operatorname{cof} 1,{ }^{61}$ DHODH has also been implicated in oxidative stress. ${ }^{82}$ Inhibition or depletion of DHODH leads to an increase in ROS production, ${ }^{83}$ which has been shown to trigger cell death. ${ }^{61}$ Thus, DHODH depletion may induce NCC progenitor cell death through mitochondrial dysfunction or increased ROS, underpinning the analogous craniofacial anomalies observed in both mandibulofacial and acrofacial dysostosis. Dietary supplementation with antioxidants such as $\mathrm{N}$-acetyl-L-cysteine could potentially ameliorate the phenotypes observed in Miller syndrome similar to that recently shown in mouse models of TCS, ${ }^{61}$ but this remains to be tested.

\section{SUMMARY, CONCLUSIONS, AND PERSPECTIVES}

Facial dysostoses comprise a group of rare clinically and etiologically heterogeneous craniofacial anomalies that arise due to defects in NCC development and their derivatives. TCS, is caused by mutations in three ribosome biogenesis-associated genes, TCOF1, POLR1C, and POLR1D (Figure 3). ${ }^{10,37}$ Work in both mouse and zebrafish has shown that TCOF1, POLR1C, and POLR1D loss-of-function leads to diminished ribosome biogenesis resulting in p53dependent apoptosis of NCC progenitors and craniofacial anomalies. ${ }^{48,65,66}$ One of the key regulators of p53 is MDM2, ${ }^{84}$ which inhibits p53, and targets it to proteasome degradation. ${ }^{85}$ Studies have shown that ribosomal proteins such as Rpl5, Rpl11, and Rpl23, for example, have a binding affinity for MDM2. ${ }^{8687-91}$ Thus, it is possible that when TCOF1, POLR1C, or POLR1D are mutated causing deficient rRNA transcription, this leads to binding of ribosomal proteins to MDM2, blocking its ligase activity, which promotes p53 activation and stabilization. ${ }^{86}$ Ultimately this results in $\mathrm{p} 53$ dependent cell death (Figure 3). 
Notably, inhibition of p53-dependent apoptosis can successfully rescue the phenotypes exhibited by Tcof $1^{+/-}$mice as well as polr1c and polr1d mutant zebrafish. ${ }^{58,65,66}$ However, p53 functions as a tumor suppressor, and inhibiting p53 could potentially lead to tumorigenic side effects emphasizing the need to explore additional avenues for preventing TCS and other ribosomopathies that affect head and facial development. Interestingly, an unexpected role for Tcof1 in DNA damage and oxidative stress was recently identified. ${ }^{61}$ Consistent with a role for Tcof1 in protection against ROS-induced DNA damage, dietary supplementation with $\mathrm{N}$-acetyl cysteine, reduced the levels of cell death and partially rescued the craniofacial phenotypes observed in $T c o f 1^{+/-}$ mouse embryos. ${ }^{61}$ This suggests that antioxidant supplementation could potentially be a promising therapy to prevent or ameliorate TCS in humans and possibly other ribosomopathies.

An association between deficient ribosome biogenesis, p53-dependent apoptosis, reduced numbers of NCC, and craniofacial anomalies appears to be a common mechanism underlying many ribosomopathies. This is true for the recently characteri redribosomopathy acrofacial dysostosis-cincinnati type, which exhibits a similar mandibulofacial phenotype as observed in TCS, but with or without the ads of limb defects. Acrofacial dysostosis-cincinnati is caused by mutations in POLR1A, which encodes the catalytic subunit of RNA polymerase I. POLR1A loss-of-function results in diminished ribosomal RNA transcription which leads to p53-dependent apoptosis of NCC progenitors and craniofacial anomalies. It is surprising that ribosome biogenesis is globally required in every cell and yet defects in this process result in tissue-specific phenotypes. However, the tissue-specific expression of ribosomal genes, as described above, could potentially account for the tissue-specific roles of ribosome biogenesis during embryogenesis. The elevated expression of ribosomeassociated genes in neuroepithelial cells and progenitor NCC may make them more sensitive to perturbations in ribosome biogenesis. The development of NCC as well as bone and cartilage are dynamic processes that require high levels of proliferation and high levels of protein synthesis. Therefore, highly proliferative tissues, such as those affected in the facial dysostoses described in this review, may require higher threshold levels of rRNA transcription, making them more sensitive to any disruption in the ribosome biogenesis pathway. Alternatively, specialized ribosomes may also play a role in the pathogenesis of ribosomopathies. ${ }^{92}$ In this scenario, core ribosome components, could act differently in specific tissues due to their interaction with transient proteins, cis-regulatory elements or other cofactors that are present within specific subsets of mRNAs. ${ }^{92}$

Acrofacial dysostoses, such as MFDM and Nager syndrome, can arise through perturbations of global processes other than ribosome biogenesis and yet still exhibit similar defects in cranial NCC and bone and cartilage development. Interestingly, these defects are attributed to disruptions in EFTUD2 in MFDM $^{69}$ and in SF3B4 in Nager syndrome, ${ }^{74}$ both proteins components of the ubiquitous pre-mRNA spliceosome complex. Despite the putative widespread need for mRNA splicing, facial dysostoses exhibit malformation of the craniofacial skeleton. The aberrant splicing of genes involved in NCC development and possibly bone and cartilage differentiation may be the cause for the tissue-specific defects observed in MDFM and Nager syndrome. Additionally, different rates of transcription and translation in different cells may also play a role. Similar to deficient ribosome biogenesis, it is possible that the highly proliferative nature of NCC, as well as bone and cartilage progenitors makes them more susceptible to defects in mRNA splicing. However, it is also possible that similar to the noncanonical function of TCOF1/Treacle in DNA damage and oxidative stress, these spliceosomal proteins may be involved in other tissue-specific complexes; for example, SF3B4 may regulate BMP signaling, which is known to play an important role in osteogenic and chondrogenic differentiation. ${ }^{77,78}$

Miller syndrome, which is characterized by defects in the craniofacial and postaxial limb sk ton, is caused by mutations in DHODH. ${ }^{80} \mathrm{DHO}$ encodes a key enzyme in de novo pyrimidine synthesis and the mitochondrial electron transport chain. Unfortunately, the mechanistic roles of these pathways in craniofacial and limb development or Miller syndrome have not been well studied. However, similar to the facial dysostoses described above, DHODH loss-of-function was found to cause apoptosis of NCC progenitors which leads to defects in craniofacial bone and cartilage development. ${ }^{81}$ Interestingly, DHODH has been found to play roles in a variety of processes including, mitochondrial membrane potential, cell proliferation, ROS production and apoptosis in specific cell types. ${ }^{83}$ One possibility is that DHODH loss-of-function disrupts the transcriptional elongation of genes specifically required for NCC, bone and cartilage development. ${ }^{81}$ Alternatively, inhibition of DHDOH may lead to increase of ROS production in the neuroepithelium, leading to cell death. Therefore, it would be interesting to test if antioxidant supplementation can ameliorate the 
phenotypes observed in DHODH-deficient zebrafish and mammalian models similar to that for TCS.

In conclusion, although acrofacial dysostoses can affect both craniofacial and limb formation, all of the syndromes described in this review primarily affect NCC-derived craniofacial bone and cartilage development. The sensitivity of NCC and skeletal development to disruptions in global process is perhaps not surprising. In fact, this seems to be a common phenomenon in ribosomopathies such as Nager syndrome and TCS as well as Diamond-Blackfan Anemia (DBA). DBA patients exhibit craniofacial defects similar to those observed in other ribosomopathies, while also exhibiting specific defects affecting bone marrow function. Differential regulation of gene expression, transcription factors or posttranslational modifications as well as the type and location of the mutation could each contribute to the underlying cause of the tissue-specific phenotypes observed in ribosomopathies and other mandibulofacial and acrofacial dysostoses. Alternatively, these tissues are highly proliferative and perhaps require relatively high levels and rates of ribosome biogenesis, mRNA splicing or other global processes. It is crucial that as we continue to investigate the developmental and disease roles for these genes and processes using animal models that we explore the possibility for interactions between each of these genes with other genes and pathways important for NCC, bone and cartilage development. There is much that remains to be learned about the spatiotemporal functional specificity of individual RNA polymerase and spliceosome complex subunits, as well as individual cell and tissue sensitivity to disruptions in ribosome biogenesis, premRNA splicing and other global processes. Understanding this is especially important for the proper treatment and care of these patients. Careful phenotypic and genotypic analysis is clinically necessary in advancing treatment, personalized care, and most importantly prevention of these congenital diseases. Although many facial dysostoses present with similar and overlapping phenotypes, their etiology, developmental history, and genetics may require different treatment regimes. ${ }^{93}$ For example, although mutations in either Tcof1, Polr1c, or Polr1d lead to TCS, successful treatment and/or prevention may depend on the specific underlying genetic mutation. A thorough understanding of the distinct signals, switches and mechanisms which regulate both, normal development and disease is still needed. ${ }^{93}$

\section{ACKNOWLEDGMENTS}

\section{REFERENCES}

1. Aoto $\mathrm{K}$ et $Q$ Mef2c-F10N enhancer driven betagalactosidase (LacZ) and Cre recombinase mice facilitate analyses of gene function and lineage fate in neural crest cells. Dev Biol 2015, 402:3-16.

2. Frisdal A, Trainor PA. Development and evolution of the pharyngeal apparatus. WIREs Dev Biol 2014, 3:403-418.

3. Trainor P, Krumlauf R. Plasticity in mouse neural crest cells reveals a new patterning role for cranial mesoderm. Nat Cell Biol 2000, 2:96-102.

4. Le Douarin N, Kalcheim C. The neural crest. Cambridge, UK: Cambridge University Press; 1999, xxiii, $445 \mathrm{pp}$.

5. Trainor PA, Tam PP. Cranial paraxial mesoderm and neural crest cells of the mouse embryo: co-distribution in the craniofacial mesenchyme but distinct segregation in branchial arches. Development 1995, 121: 2569-2582.

6. Trainor PA, Tan SS, Tam PP. Cranial paraxial mesoderm: regionalisation of cell fate and impact on craniofacial development in mouse embryos. Development 1994, 120:2397-2408.

7. Noden DM, Trainor PA. Relations and interactions between cranial mesoderm and neural crest populations. J Anat 2005, 207:575-601.

8. Trainor P. Molecular blueprint for craniofacial morphogenesis and development. In: Huang GT-J, Thesleff I, eds. Stem Cells in Craniofacial Developmen and Regeneration. Hoboken, NJ: Wiley; 2013, 3-29.

9. Rovin S, Dachi SF, Borenstein DB, Cotter WB. Mandibulofacial dysostosis, a familial study of five generations. J Pediatr 1964, 65:215-221.

10. The Treacher Collins Syndrome Collaborative Group. Positional cloning of a gene involved in the pathogenesis of Treacher Collins syndrome. Nat Genet 1996, 12:130-136. 
11. Dixon MJ, Marres HA, Edwards SJ, Dixon J, Cremers CW. Treacher Collins syndrome: correlation between clinical and genetic linkage studies. Clin Dysmorphol 1994, 3:96-103.

12. Marres HA, Cremers CW, Dixon MJ, Huygen PL, Joosten FB. The Treacher Collins syndrome. A clinical, radiological, and genetic linkage study on two pedigrees. Arch Otolaryngol Head Neck Surg 1995, 121:509-514.

13. Edwards SJ et al. Prenatal diagnosis in Treacher Collins syndrome using combined linkage analysis and ultrasound imaging. J Med Genet 1996, 33:603-606.

14. Fang J et al. Protein instability and functional defects caused by mutations of dihydro-orotate dehydrogenase in Miller syndrome patients. Biosci Rep 2012, 32:631-639.

15. Rainger J et al. Miller (Genee-Wiedemann) syndrome represents a clinically and biochemically distinct subgroup of postaxial acrofacial dysostosis associated with partial deficiency of DHODH. Hum Mol Genet 2012, 21:3969-3983.

16. Hall BD. Nager acrofacial dysostosis: autosomal dominant inheritance in mild to moderately affected mother and lethally affected phocomelic son. Am J Med Genet 1989, 33:394-397.

17. Chemke J, Mogilner BM, Ben-Itzhak I, Zurkowski L, Ophir D. Autosomal recessive inheritance of Nager acrofacial dysostosis. J Med Genet 1988, 25:230-232.

18. Aylsworth AS, Lin AE, Friedman PA. Nager acrofacial dysostosis: male-to-male transmission in 2 families. Am J Med Genet 1991, 41:83-88.

19. Weaver $\mathrm{KN}$ et al. Acrofacial dysostosis, cincinnati type, a mandibulofacial dysostosis syndrome with limb anomalies, is caused by polr1a dysfunction. Am J Hum Genet 2015, 96:765-774.

20. Fazen LE, Elmore J, Nadler HL. Mandibulo-facial dysostosis. (Treacher-Collins syndrome). Am J Dis Child 1967, 113:405-410.

21. Phelps PD, Poswillo D, Lloyd GA. The ear deformities in mandibulofacial dysostosis (Treacher Collins syndrome). Clin QDlaryngol Allied Sci 1981, 6:15-28.

22. Wise CA et al. TCOF1 gene encodes a putative nucleolar phosphoprotein that exhibits mutations in Treacher Collins Syndrome throughout its coding region. Proc Natl Acad Sci U S A 1997, 94:3110-3115.

23. Dixon $J$ et al. Identification of the complete coding sequence and genomic organization of the Treacher Collins syndrome gene. Genome Res 1997, 7:223-234.

24. So RB GB, Henning D, Dixon J, Dixon MJ, Valdez BC. Another face of the Treacher Collins syndrome (TCOF1) gene: identification of additional exons. Gene 2004, 49-57.

25. Gladwin AJ et al. Hreacher Collins syndrome may result from insertions, deletions or splicing mutations, which introduce a termination codon into the gene. Hum Mol Genet 1996, 5:1533-1538.

26. Edwards SJ, Gladwin AJ, Dixon MJ. The mutational spectrum in Treacher Collins syndrome reveals a predominance of mutations that create a prematuretermination codon. Am J Hum Genet 1997, 60:515-524.

27. Dixon J, Ellis I, Bottani A, Temple K, Dixon MJ. Identification of mutations in TCOF1: use of molecular analysis in the pre- and postnatal diagnosis of Treacher Collins syndrome. Am J Med Genet A 2004, 127A:244-248.

28. Splendore A et al. High mutation detection rate in TCOF1 among Treacher Collins syndrome patients reveals clustering of mutations and 16 novel pathogenic changes. Hum Mutat 2000, 16:315-322.

29. Splendore A, Jabs EW, Passos-Bueno MR. Screening of TCOF1 in patients from different populations: confirmation of mutational hot spots and identification of a novel missense mutation that suggests an important functional domain in the protein treacle. J Med Genet 2002, 39:493-495.

30. Splendore A, Fanganiello RD, Masotti C, Morganti LS, Passos-Bueno MR. TCOF1 mutation database: novel mutation in the alternatively spliced exon $6 \mathrm{~A}$ and update in mutation nomenclature. Hum Mutat 2005, 25:429-434.

31. Teber OA et al. Genotyping in 46 patients with tentative diagnosis of Treacher Collins syndrome revealed unexpected phenotypic variation. Eur J Hum Genet 2004, 12:879-89

32. Bowman $\mathrm{M}$ et a. Gross deletions in TCOF1 are a cause of Treacher-Collins-Franceschetti syndrome. Eur J Hum Genet2012, 20:769-777.

33. Beygo $\mathrm{J}$ et al $\mathrm{P}$ treport of a single exon deletion in TCOF1 causing Treacher Collins syndrome. Mol Syndromol 2012, 2:53

34. Masotti $C$ et al. Reduced transcription of TCOF1 in adult cells of Treacher Collins syndrome patients. BMC Med Genet 2009, 10:136.

35. Jones KL, Smith DW, Harvey MA, Hall BD, Quan L. Older paternal age and fresh gene mutation: data on additional disorders. J Pediatr 1975, 86:84-88.

36. Saudi Mendeliome G. Comprehensive gene panels provide advantages over clinical exome sequencing for Mendelian diseases. Genome Biol 2015, 16:134.

37. Dauwerse JG et al. Mutations in genes encoding subunits of RNA polymerases I and III cause Treacher Collins syndrome. Nat Genet 2011, 43:20-22.

38. Yao Y, Yamamoto K, Nishi Y, Nogi Y, Muramatsu M. Mouse RNA polymerase I 16-kDa subunit able to associate with $40-\mathrm{kDa}$ subunit is a homo$\log$ of yeast AC19 subunit of RNA polymerases I and III. J Biol Chem 1996, 271:32881-32885. 
39. Vincent $M$ et al. Treacher Collins syndrome: a clinical and molecular study based on a large series of patients. Genet Med 2 18:49-56.

40. Isaac $\mathrm{C}$ et al. Characterization of the nucleolar gene product, treacle, in Treacher Collins syndrome. Mol Biol Cell 2000, 11:3061-3071.

41. Marsh KL, Dixon J, Dixon MJ. Mutations in the Treacher Collins syndrome gene lead to mislocalization of the nucleolar protein treacle. Hum Mol Genet 1998, 7:1795-1800.

42. Winokur ST, Shiang R. The Treacher Collins syndrome (TCOF1) gene product, treacle, is targeted to the nucleolus by signals in its C-terminus. Hum Mol Genet 1998, 7:1947-1952.

43. Valdez BC, Henning D, So RB, Dixon J, Dixon MJ. The Treacher Collins syndrome (TCOF1) gene product is involved in ribosomal DNA gene transcription by interacting with upstream binding factor. Proc Natl Acad Sci U S A 2004 11:10709-10714.

44. Gonzales B et al. The Treacher Collins syndrome (TCOF1) gene product is involved in pre-rRNA methylation. Hum Mol 2005, 14:2035-2043.

45. Hayano $\mathrm{T}$ et al. Steomic analysis of human Nop56p-associated pre-ribosomal ribonucleoprotein complexes. Possible link between Nop56p and the nucleolar protein treacle responsible for Treacher Collins syndrome. J Biol Chem 2003, 278:34309-34319.

46. Lin CI, Yeh NH. Treacle recruits RNA polymerase I complex to the nucleolus that is independent of UBF. Biochem Biophys Res Commun 2009, 386:396-401.

47. Dixon J, Hovanes K, Shiang R, Dixon MJ. Sequence analysis, identification of evolutionary conserved motifs and expression analysis of murine tcof1 provide further evidence for a potential function for the gene and its human homologue, TCOF1. Hum Mol Genet 1997, 6:72 27 .

48. Dixon J et al. Tcof1/Treacle is required for neural crest cell formation and proliferation deficiencies that cause craniofacial abnormalities. Proc Natl Acad Sci U S A 2006, 103:13403-13408.

49. Dixon J, Brakebusch C, Fassler R, Dixon MJ. Increased levels of apoptosis in the prefusion neural folds underlie the craniofacial disorder, Treacher Collins syndrome. Hum Mol Genet 2000, 9:1473-1480.

50. Dixon J, Dixon MJ. Genetic background has a major effect on the penetrance and severity of craniofacial defects in mice heterozygous for the gene encoding the nucleolar protein Treacle. Dev Dyn 2004, 229:907-914.

51. Richter CA et al. Defects in middle ear cavitation cause conductive hearing loss in the Tcof1 mutant mouse. Hum Mol Genet 2010, 19:1551-1560.

52. Sakai D, Dixon J, Dixon MJ, Trainor PA. Mammalian neurogenesis requires Treacle-Plk1 for precise control of spindle orientation, mitotic progression, and maintenance of neural progenitor cells. PLoS Genet 2012, 8:e100256@

53. Conley ZR et al. A quantitative method for defining high-arched palate using the Tcof1(+/-) mutant mouse as a model. Dev Biol 2016, 415:296-305.

54. Poswillo D. The pathogenesis of the Treacher Collins syndrome (mandibulofacial dysostosis). Br J Oral Surg 1975, 13:1-26.

55. Chakraborty A, Uechi T, Kenmochi N. Guarding the 'translation apparatus': defective ribosome biogenesis and the p53 signaling pathway. WIREs RNA 2011, 2:507-522.

56. Garden GA, Hartlage-Rubsamen M, Rubel EW, Bothwell MA. Protein masking of a ribosomal RNA epitope is an early event in afferent deprivationinduced neuronal death. Mol Cell Neurosci 1995, 6:293-310.

57. Werner A et al. Cell-fate determination by ubiquitindependent regulation of translation. Nature 2015, 525:523-527.

58. Jones NC et al. Prevention of the neurocristopathy Treacher Collins syndrome through inhibition of p53 function. Nat Med 2008, 14:125-133.

59. Levine AJ. p53, the cellular gatekeeper for growth and division. Cell 1997, 23-331.

60. Komarov PG et al. 1 hemical inhibitor of $\mathrm{p} 53$ that protects mice from the side effects of cancer therapy. Science 1999, 285:1733-1737.

61. Sakai D, Dixon J, Achilleos A, Dixon M, Trainor PA. Prevention of Treacher Collins syndrome craniofacial anomalies in mouse models via maternal antioxidant supplementation. Nat Commun 2016, 7:10328.

62. Kuo LJ, Yang LX. Gamma-H2AX - a novel biomarker for DNA double-strand breaks. In Vivo 2008, 22:305-309.

63. Larsen DH et al. The NBS1-Treacle complex controls ribosomal RNA transcription in response to DNA damage. Nat Cell Biol 2014, 16:792-803.

64. Ciccia A et al. Treacher Collins syndrome TCOF1 protein cooperates with NBS1 in the DNA damage response. Proc Natl Acad Sci U S A 2014, 111:18631-18636.

65. Noack Watt KE, Achilleos A, Neben CL, Merrill AE, Trainor PA. The roles of RNA polymerase I and III subunits Polr1c and Polr1d in craniofacial development and in zebrafish models of Treacher Collins Syndrome. PLoS G 2016, 12:e1006187.

66. Lau MC et al. Pathogenesis of POLR1C-dependent Type 3 Treacher Collins Syndrome revealed by a zebrafish model. Biochim Biophys Acta 2016.

67. Trainor PA, Andrews BT. Facial dysostoses: etiology, pathogenesis and management. Am J Med Genet C Semin Med Genet 2013, 163C:283-294.

68. Guion-Almeida ML, Zechi-Ceide RM, Vendramini S, Tabith Junior A. A new syndrome with growth and 
mental retardation, mandibulofacial dysostosis, microcephaly, and cleft palate. Clin Dysmorphol 2006, 15:171-174.

69. Luquetti DV et al. Mandibulofacial dysostosis with microcephaly" caused by EFTUD2 mutations: expanding the phenotype. Am J Med Genet A 2013, 161A:108-11?

70. Nur BG et al. Sible autosomal recessive inheritance in an infant with acrofacial dysostosis similar to Nager syndrome. Am J Med Genet A 2013, 161A:2311-2315.

71. Deml B, Reis LM, Muheisen S, Bick D, Semina EV. EFTUD2 deficiency in vertebrates: Identification of a novel human mutation and generation of a zebrafish model. Birth Defects Res A Clin Mol Teratol 2015, 103:630-640.

72. Devotta A, Juraver-Geslin H, Gonzalez JA, Hong CS, Saint-Jeannet JP. Sf3b4-depleted Xenopus embryos: a model to study the pathogenesis of craniofacial defects in Nager syndrome. Dev Biol 2016.

73. Czeschik JC et al. Clinical and mutation data in 12 patients with the clinical diagnosis of Nager syndrome. Hum Genet 2013, 132:885-898.

74. Bernier FP et al. Haploinsufficiency of SF3B4, a component of the pre-mRNA spliceosomal complex, causes Nager syndrome. Am J Hum Genet 2012, 90:925-933.

75. Kennedy SJ, Teebi AS. Newly recognized autosomal recessive acrofacial dysostosis syndrome resembling Nager syndrome. Am J Med Genet A 2004, 129A:73-76.

76. Petit F et al. Nager syndrome: confirmation of SF3B4 haploinsufficiency as the major cause. Clin Genet 2014, 86:246-251.

77. Robert B. Bone morphogenetic protein signaling in limb outgrowth and patterning. Dev Growth Differ 2007, 49:455-468.

78. Watanabe $\mathrm{H}$, Shionyu M, Kimura T, Kimata K, Watanabe H. Splicing factor $3 \mathrm{~b}$ subunit 4 binds BMPR-IA and inhibits osteochondral cell differentiation. J Biol Chem 2007, 282:20728-20738.

79. Miller M, Fineman R, Smith DW. Postaxial acrofacial dysostosis syndrome. J Pediatr 1979, 95:970-975.

80. $\mathrm{Ng} \mathrm{SB}$ et al. Exome sequencing identifies the cause of a mendelian disorder. Nat Genet 2010, 42:30-35.
81. White RM et al. DHODH modulates transcriptional elongation in the neural crest and melanoma. Nature 2011, 471:518-522.

82. Hail N Jr, Chen P, Kepa JJ, Bushman LR, Shearn C. Dihydroorotate dehydrogenase is required for $\mathrm{N}-(4$ hydroxyphenyl)retinamide-induced reactive oxygen species production and apoptosis. Free Radic Biol Med 2010, 49:10 6 .

83. Fang $\mathrm{J}$ et al. Dihydro-orotate dehydrogenase is physically associated with the respiratory complex and its loss leads to mitochondrial dysfunction. Biosci Rep 2013, 33:e0021.

84. Haupt Y, Maya R, Kazaz A, Oren M. Mdm2 promotes the rapid degradation of p53. Nature 1997, 387:296-299.

85. Toledo F, Wahl GM. Regulating the p53 pathway: in vitro hypotheses, in vivo veritas. Nat Rev Cancer 2006, 6:909-92@

86. Sagar V et al. PIM1 destabilization activates a p53dependent response to ribosomal stress in cancer cells. Oncotarget 2016, 7:23837-23849.

87. Bhat KP, Itahana K, Jin A, Zhang Y. Essential role of ribosomal protein L11 in mediating growth inhibitioninduced p53 activation. EMBO J 2004, 23:2402-2412.

88. Dai MS, Lu H. Inhibition of MDM2-mediated p53 ubiquitination and degradation by ribosomal protein L5. J Biol Chen 20 4, 279:44475-44482.

89. Dai MS et al. Ribosomal protein L23 activates p53 by inhibiting MDM2 function in response to ribosomal perturbation but not to translation inhibition. Mol Cell Biol 2004, 24:7654-7668.

90. Lohrum MA, Ludwig RL, Kubbutat MH, Hanlon M, Vousden KH. Regulation of HDM2 activity by the ribosomal protein L11. Cancer Cell 2003, 3:577-587.

91. Marechal V, Elenbaas B, Piette J, Nicolas JC, Levine AJ. The ribosomal L5 protein is associated with mdm-2 and mdm-2-p53 complexes. Mol Cell Biol 1994, 14:7414-7420.

92. Xue S, Barna M. Specialized ribosomes: a new frontier in gene regulation and organismal biology. Nat Rev Mol Cell Biol 2012, 13:355-369.

93. Trainor PA, Richtsmeier JT. Facing up to the challenges of advancing craniofacial research. Am J Med Genet A 2015, 167:1451-1454. 


\section{$\begin{array}{lr}\text { Graphical abstract } & 57\end{array}$}

\section{Rare syndromes of the head and face: mandibulofacial and acrofacial dysostoses}

Karla Terrazas $^{1}$, Jill Dixon ${ }^{2}$, Paul A. Trainor ${ }^{1,3}$, Michael J. Dixon ${ }^{2}$

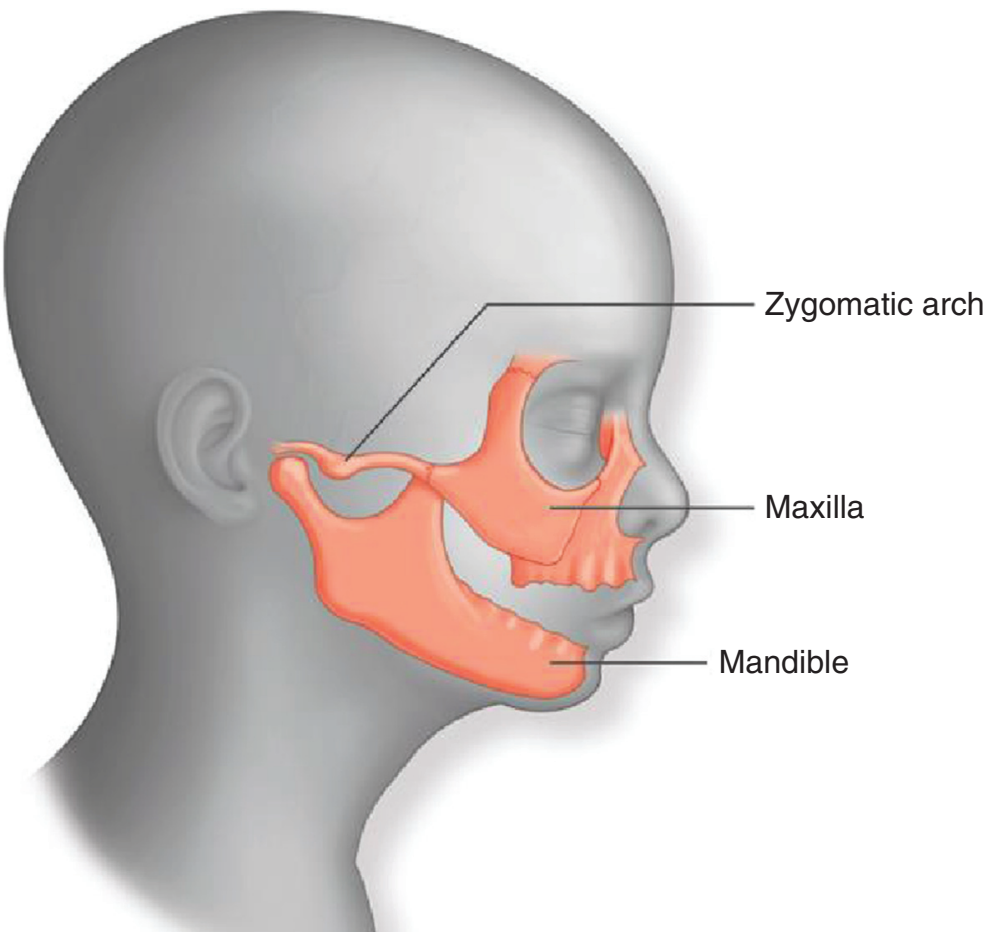

Craniofacial anomalies account for approximately one-third of all congenital birth defects. Here, we discuss the pathogenesis of a specific array of craniofacial anomalies, termed facial dysostoses, which affect development of the maxilla, mandible, and zygomatic arch.

\section{.} . . 
QUERIES TO BE ANSWERED BY AUTHOR

IMPORTANT NOTE: Please mark your corrections and answers to these queries directly onto the proof at the relevant place. DO NOT mark your corrections on this query sheet.

\section{Queries from the Copyeditor:}

AQ1. Please confirm that given names (red) and surnames/family names (green) have been identified correctly.

AQ2. We have provided this standard statement as per journal style. Please modify only if you have any conflict to declare, else retain the same.

AQ3. Please check whether the hierarchy of heading levels has been identified correctly for the article.

AQ4. Please check whether "at" in the phrase "migrating crest cells at E8.0 to E8.5" can be changed to "from".

AQ5. Please provide the expansion for QRT-PCR.

AQ6. If there are fewer than 10 authors for et al.-type references please supply all of their names. If there are 10 or more authors, please supply the first 10 authors' names then et al.

AQ7. Please provide Volume number, Page range for ref. [66].

AQ8. Please provide Volume number, Page range for ref. [72]. 
Required software to e-Annotate PDFs: Adobe Acrobat Professional or Adobe Reader (version $\mathbf{7 . 0}$ or above). (Note that this document uses screenshots from Adobe Reader $\mathbf{X}$ )

The latest version of Acrobat Reader can be downloaded for free at: http://get.adobe.com/uk/readerl

Once you have Acrobat Reader open on your computer, click on the Comment tab at the right of the toolbar:

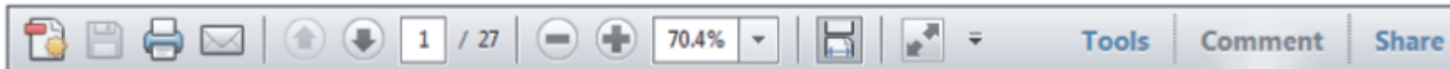

This will open up a panel down the right side of the document. The majority of tools you will use for annotating your proof will be in the Annotations section, pictured opposite. We've picked out some of these tools below:

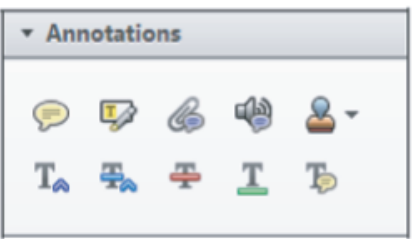

1. Replace (Ins) Tool - for replacing text.

军 Strikes a line through text and opens up a text box where replacement text can be entered.

\section{How to use it}

- Highlight a word or sentence.

- Click on the Replace (Ins) icon in the Annotations section.

- Type the replacement text into the blue box that appears.

1dard tramework for the analysis of $\mathrm{m}$ icy Nevertheless, it alse-led to exog،

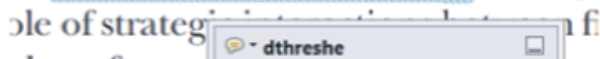
aber of comp 08/06/2011 15:58:17 : is that the $\mathrm{si}$, which led of nain compo bo level, are exc nc

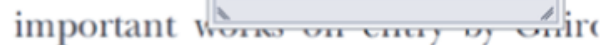
M heneferth) 1 we snen the 'hlarl 1

3. Add note to text Tool - for highlighting a section to be changed to bold or italic.

T. Highlights text in yellow and opens up a text box where comments can be entered.

\section{How to use it}

- Highlight the relevant section of text.

- Click on the Add note to text icon in the Annotations section.

- Type instruction on what should be changed regarding the text into the yellow box that appears.

namic responses of mark ups ent with the VAR evidence

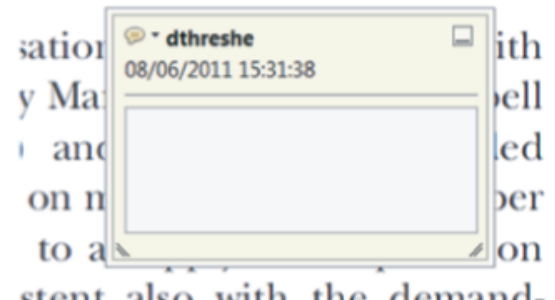

2. Strikethrough (Del) Tool - for deleting text.

Strikes a red line through text that is to be deleted.

\section{How to use it}

- Highlight a word or sentence.

- Click on the Strikethrough (Del) icon in the Annotations section.

there is no room for extra prohts al : ups are zero and the number of set) values are not determined by Blanchard and Kivetaki (1987), sfect competition in general equilil ts of aggregate demand and supply lassical framework assuming monol een on evorensue number of firms

4. Add sticky note Tool - for making notes at specific points in the text.

Marks a point in the proof where a comment needs to be highlighted.

How to use it

- Click on the Add sticky note icon in the Annotations section.

- Click at the point in the proof where the comment should be inserted.

- Type the comment into the yellow box that appears.

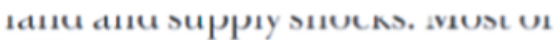

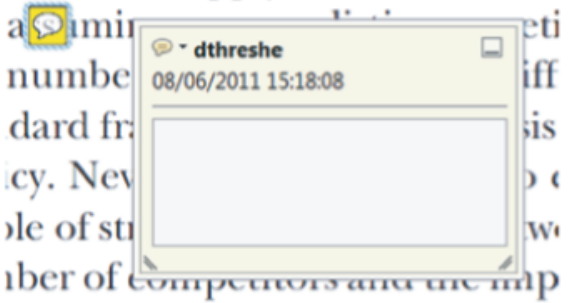

is that the structure of the sects: 
5. Attach File Tool - for inserting large amounts of text or replacement figures.

Inserts an icon linking to the attached file in the appropriate pace in the text.

\section{How to use it}

- Click on the Attach File icon in the Annotations section.

- Click on the proof to where you'd like the attached file to be linked.

- Select the file to be attached from your computer or network.

- Select the colour and type of icon that will appear in the proof. Click OK.

\section{E N D}

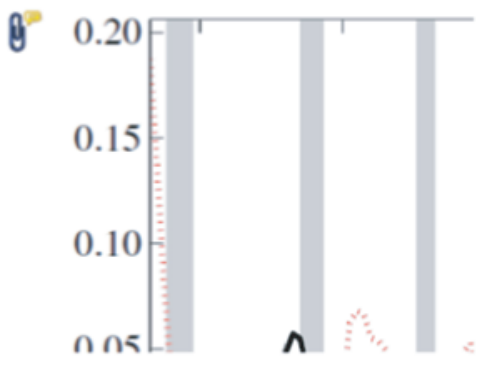

6. Add stamp Tool - for approving a proof if no corrections are required.

- Inserts a selected stamp onto an appropriate place in the proof.

\section{How to use it}

- Click on the Add stamp icon in the Annotations section.

- Select the stamp you want to use. (The Approved stamp is usually available directly in the menu that appears).

- Click on the proof where you'd like the stamp to appear. (Where a proof is to be approved as it is, this would normally be on the first page).

tr the Dusiness cycie, starung with the on perfect competition, constant ret hy otaki (1987), has introduced produc general equilibrium models with nomin:

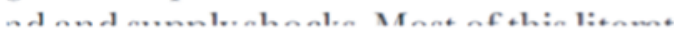

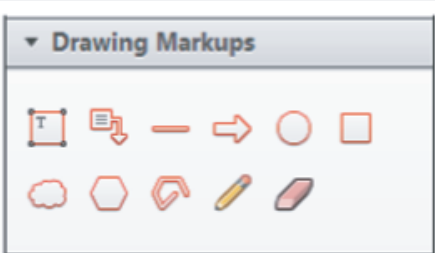

\section{How to use it}

- Click on one of the shapes in the Drawing Markups section.

- Click on the proof at the relevant point and draw the selected shape with the cursor.

- To add a comment to the drawn shape, move the cursor over the shape until an arrowhead appears.

- Double click on the shape and type any text in the red box that appears.
7. Drawing Markups Tools - for drawing shapes, lines and freeform annotations on proofs and commenting on these marks.

Allows shapes, lines and freeform annotations to be drawn on proofs and for comment to be made on these marks..

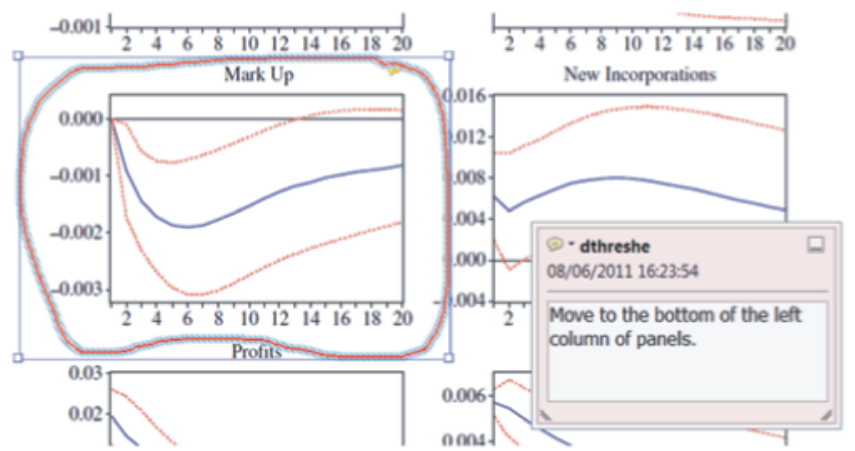

For further information on how to annotate proofs, click on the Help menu to reveal a list of further options:

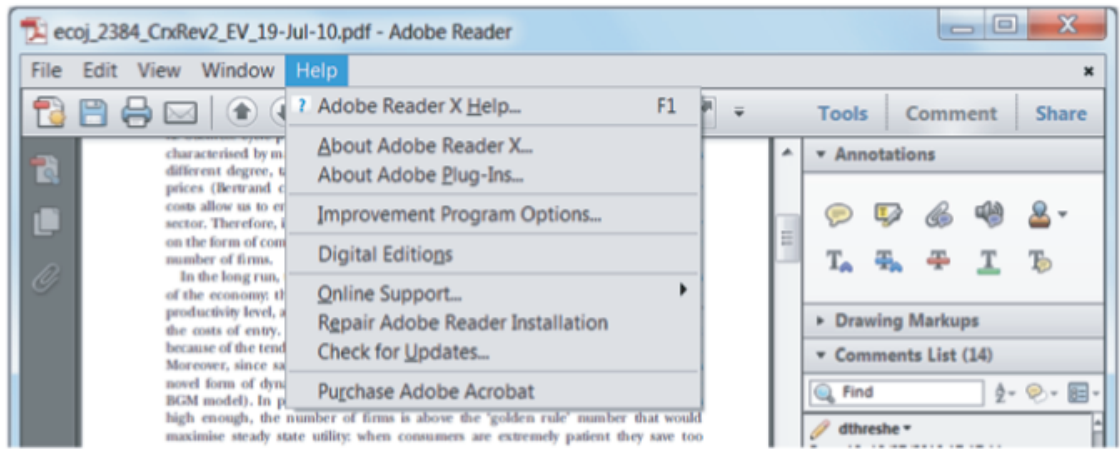

